See discussions, stats, and author profiles for this publication at: https://www.researchgate.net/publication/348397155

\title{
Short and long term efficacy and prevalence of Cryphonectria parasitica hypovirulent strains released as biocontrol agents of chestnut blight
}

Article in European Journal of Plant Pathology · January 2021

DOI: 10.1007/s10658-021-02200-3

CITATION

1

3 authors:

Valentim Coelho

Instituto Politécnico de Bragança

42 PUBLICATIONS 168 CITATIONS

SEE PROFILE

eugénia Gouveia

Instituto Politécnico de Bragança

33 PUBLICATIONS 76 CITATIONS

SEE PROFILE
READS

15

2uís Nunes

68 PUBLICATIONS 220 CITATIONS

SEE PROFILE

Some of the authors of this publication are also working on these related projects:

PTDC/AGR-CFL/68186/2006, "Mixed forests. Modelling, dynamics and geographical distribution of productivity and carbon storage in mixed forest ecosystems in portugal" View project

Program of biological control for the Chestnut blight (Cryphonectria parasitica) treatment in Portugal View project 


\title{
Short and long term efficacy and prevalence of Cryphonectria parasitica hypovirulent strains released as biocontrol agents of chestnut blight
}

\author{
Valentim Coelho - Luís Nunes (D) Eugénia Gouveia (D)
}

\begin{abstract}
Chestnut blight, Cryphonectria parasitica (Murrill) Barr, was reported in Portugal in 1989. The disease rapidly spread within the chestnut region of the Trás-os-Montes (the Northeast of Portugal). Eradication and mechanical/burning exclusion failed to control the disease and natural hypovirulence is still absent or of very low incidence. The introduction of human-assisted therapeutic hypovirulence is therefore required to control the disease. We presente here the efficacy of field applications (short and long term) of a locally characterized hypovirulent strain (CHV1-RBB111), by the punch method in two chestnut orchards (Valpaços and Vinhais). The Valpaços disease incidence was $68 \%$ (65 out of 96 trees) and in Vinhais it was $46 \%$ (78 out of 169 trees). In both locations, diversity of vegetative incompatibility (vc type) was low and largely dominated (> $85 \%$ ) by a single ve type (EU11). In Valpaços, all cankers of the orchard were treated (63 cankers) and in Vinhais 31 trees (cankers) were treated. One year after application, field efficacy was very high with $93.8 \%$ of healed cankers in Valpaços and $90.3 \%$ in Vinhais, these
\end{abstract}

\footnotetext{
V. Coelho · L. Nunes · E. Gouveia $(\bowtie)$

Centro de Investigação de Montanha, Instituto Politécnico de Bragança, Campus de Santa Apolónia, 5300-253 Bragança, Portugal

e-mail: egouveia@ipb.pt
}

\author{
V. Coelho \\ e-mail: valentimcoelho@ipb.pt \\ L. Nunes \\ e-mail: 1fnunes@ipb.pt
}

values increased to $100 \%$ and $93.5 \%$ (respectively) after four years. The persistence of the introduced CHV1RBB 111 strain was high and present in almost all treated cankers and it was dominant both inwards and on the application site revealing an endophytic behavior. The non- $C$. parasitica microfungi were abundant with 14 different species. Biscogniauxia mediterranea (De Not.) Kuntze was the most abundant in both orchards. Treatment with the introduced hypovirulent strain (CHV1-RBB111) was found to be effective in controlling chestnut blight with regeneration of cortical tissues and recovery of treated trees.

Keywords Chestnut blight . Cryphonectria parasitica (Murr.) Barr. · Human-assisted therapeutic hypovirulence · Hypovirulent strain CHV1-RBB111

\section{Introduction}

Despite a first report of Cryphonectria parasitica (Murr.) Barr. in Portugal as long ago as 1922, obtained from bark samples of Castanea dentata (Sieb. \& Zucc.) (Câmara 1929), no further evidence occurred until 1989 when the disease was found in new plantations in Valpaços and Bragança and almost at the same time in Vinhais (Abreu 1992). The disease rapidly spread affecting the fruit and wood production of the Trás-osMontes (northeastern Portugal) where $80 \%$ of chestnut production occurs. In the 1990 s, eradication and mechanical/burning of diseased tissues was applied to control the disease. The methods generally failed, and 
the disease has continued to spread over time. In the 2000s the disease was present throughout the country, including Madeira and the Azores islands (Bragança et al. 2007).

The serious phytosanitary situation of the chestnut tree in Portugal demands effective means to control the disease. Hypovirulence is a biological process, mediated by the presence of Cryphonectria hypovirus 1 (CHV1) that reduces the virulence of the fungus $C$. parasitica, which promotes canker healing and chestnut recovery (Heiniger and Rigling 1994; Hoegger et al. 2003; Robin et al. 2010). This biological control method is very effective when the population structure of the vic genes of the parasitic fungus is known, and the compatible hypovirulent strains are applied (Anagnostakis et al. 1986; Heiniger and Rigling 1994). In Portugal, the population of C. parasitica is essentially clonal and dominated by vc type EU11, although other vc types, namely, EU01, EU02, EU12 and EU66 are also present and sometimes represented by a few or single isolates (Bragança et al. 2007; Gouveia et al. 2016). Hypovirulence is not frequent in the initial phases of the disease (Robin and Heiniger 2001), and in Portugal, the introduction of hypovirulence was detected only after 18 years of chestnut blight. The white morphology of $C$. parasitica grown on PDA was obtained in 2005 in one single isolate out of 617 studied isolates (Bragança et al. 2007). In 2010, more cases of healed cankers were reported by farmers and the CHV1 hypovirus was isolated and characterized (Gouveia et al. 2010). The isolation, identification, and molecular characterization of $C$. parasitica hypovirulent strains obtained in the region, which are compatible with current vc types, makes hypovirulence a preferential strategy for controlling chestnut blight in Portugal. Hypovirulent strains can only be applied as plant protection products if they are first assessed for adverse effects on human health and the environment. For that, a large set of data is required to evaluate whether or not the biocontrol agent or its metabolites pose any acceptable toxicological and/ or ecotoxicological risks as defined by Regulation (EC) No 1107/2009. Field applications of hypovirulent strains are a necessary step therefore to studying their behavior under natural conditions in controlled field trials. Extended programs have been applied in many European countries, to study efficacy, survival, and the non-target effects of hypovirulent strains (Robin et al. 2000; Milgroom and Cortesi 2004; Heiniger and Rigling 2009; Zamora et al. 2014; Chira et al. 2017; Krstin et al. 2017; Diamandis 2018); new formulations and delivery methods have also been tested (Kunova et al. 2016).

In Portugal, due to the failure of the eradication approach and the absence or very low incidence of natural hypovirulence, more adequate and efficient control measures are required to avoid the spread of the disease in the chestnut ecosystem. In this regard, a biological control plan for canker treatment, based on compatible hypovirulent strains, has been authorized by the competent authorities in Portugal, for experimental field applications.

The success of canker treatment was evaluated following the introduction of the hypovirulent strains by the morphological evaluation of treated cankers (presence of healing tissue), the re-isolation of $C$. parasitica hypovirulent strain, and the identification of Cryphonectria hypovirus 1 (CHV1). Additionally, we also recorded and analyzed a complex mixture of microfungi, frequently unnoticed, but which are present in the majority of cankers despite their unclear role in disease recovery or maintenance.

The objective of this study was to monitor and evaluate the efficacy of treatments and obtain epidemiological parameters to obtain comprehensive and consistent information on the broader introduction of the CHV1 hypovirulent strain in the chestnut ecosystems. We also set out to monitor the cankers healing processes, the frequency of virulent and hypovirulent $C$. parasitica and the non-C. parasitica microfungi species associated with treated cankers, to expand our understanding of the hypovirulence process in the field and to formulate adequate disease management strategies.

\section{Material and methods}

Field study sites and biological control treatments

The study was conducted in two chestnut orchards located in the region of Trás-os-Montes (Northeast Portugal), namely in Rio Bom (County of Valpaços) and Vilar de Peregrinos (County of Vinhais). On both sites, the trees were georeferenced and mapped using GIS 
analysis tools and ArcView® 10.1 software (Environmental Systems Research Institute, Inc.). In Valpaços $\left(41^{\circ} 33^{\prime} 48^{\prime \prime} \mathrm{N}, 7^{\circ} 28^{\prime} 43^{\prime \prime} \mathrm{W}\right.$; 855 m.a.s.l.), the orchard covers an area of 1 ha with trees approximately 25 years old belonging to cv. Judia and spaced $10 \times 10 \mathrm{~m}$ apart. In 2014 , about $68 \%$ ( 65 out of 96 trees) of the trees were reported to have chestnut blight symptoms. In the Vinhais $\left(41^{\circ} 39^{\prime} 32\right.$ “N, 6050’32”W; 873 m.a.s.l.) orchard, a plot of 3 ha was selected, with trees approximately 25 years old of the cv. Longal and spaced $10 \times$ $10 \mathrm{~m}$ apart. In this plot, about $46 \%$ of the chestnut trees presented chestnut blight symptoms.

The vc types of the $C$. parasitica isolates were identified at both sites before commencement of the hypovirulence treatment and belong mostly to vc type EU11-90.8\% (59 out of 65 isolates) in Valpaços and $85.7 \%$ (30 out of 35 ) isolates) in Vinhais. The vc type EU66 represented $6.2 \%$ (four out of 65 isolates) in Valpaços and $2.9 \%$ (one out of 35 isolates) in Vinhais. In Valpaços, $3.0 \%$ (two out of 65 isolates) were vc type EU12 while in Vinhais 11.4\% (four out of 35 isolates) were EU12. White mycelium and the production of few or no spores, being the first step in detecting the hypovirulent phenotype, were not observed in the studied C. parasitica population.

All trees showing infection by $C$. parasitica, and presenting the vc type EU11 and EU66, were treated with the same hypovirulent strain in both selected plots (in previous laboratory studies, it had been verified that CHV1 is transmitted from the hypovirulent strain CHV1-RBB111 to virulent isolates of ve type EU11 and EU66 (data not shown). The trees with cankers of vc type EU12 were not treated by this method. In these trees, the inoculum was removed, and canker wounds were coated with cupric products.

The hypovirulent strain was applied during the months of June and July 2014 by the margin punch method. In Valpaços 65 diseased trees were treated, and in Vinhais, 31.

The CHV1 used for treatment was the strain CHV1RBB111 preserved in the fungal collection of the Instituto Politécnico de Bragança (IPB-RBB111) and in the international collection of the Micoteca of the University of Minho (MUM 14.70). This strain was obtained in 2011 in the Valpaços region and it had been used in previous studies (Pereira et al. 2015). The strain is characterized by having a white morphology in PDA culture medium and reduced conidiation. This strain when inoculated in active cankers, had the ability to heal them quickly. In this isolate the presence of CHV1 Of the Italian subtype (CHV1-1) was identified.

Evaluation of canker treatment efficacy

To evaluate the efficacy of treatments, the cankers were assessed after one and four years following treatment, to measure the performance of the application method. The evaluation was made by visual observations of the morphological characteristics of the cankers. All cankers which did not show expansion of disease beyond the site of application, with healing tissue in the diseased area, were considered to have been healed. Data were expressed as a percentage of treatment efficacy in each canker.

Canker sampling and isolation of Cryphonectria parasitica (virulent and hypovirulent strains) and non-Cryphonectria parasitica microfungi

In order to assess the presence of $C$. parasitica (virulent and hypovirulent strains) and non-C. parasitica microfungi seven healed cankers were randomly chosen at each site. Sampling was performed in February 2018, 4 years after initial treatment. To obtain $C$. parasitica isolates from the healed cankers, small sections of plant tissue were removed using a $\mathrm{T}$ Lok ${ }^{\mathrm{TM}}$ puncture biopsy needle of $4.18 \mathrm{~mm}$ of diameter (Jorgensen Laboratories, Inc.). The tissues were removed at the four cardinal points in each healed canker and at three levels: one on the application site (margin of canker), $3 \mathrm{~cm}$ inwards, and $3 \mathrm{~cm}$ outwards (total of 12 samples per canker). A total of 168 bark samples were collected from both sites. In each canker the percentage of virulent and hypovirulent isolates of $C$. parasitica and other microfungi was calculated.

In the laboratory, samples were immersed in $50 \%(\mathrm{v} /$ v) ethanol for $3 \mathrm{~min}$. The samples were then passed through the flame to remove excess ethanol and placed in Petri dishes ( $90 \mathrm{~mm}$ of diameter) with PDA (Potato Dextrose Agar - Difco, $39 \mathrm{~g} / \mathrm{L}$ ). Plates were incubated at $25 \pm 2{ }^{\circ} \mathrm{C}$ in the dark and were daily observed for microbial growth. Single colonies were transferred to new PDA plates to obtain pure isolates for subsequent identification.

The pure cultures of each fungus were preserved in agar-containing tubes and kept at $4{ }^{\circ} \mathrm{C}$, and then deposited in the fungal collection of the Laboratory of Plant 
Protection at the Instituto Politécnico de Bragança (Portugal).

\section{Incidence of hypovirulent strains in healed cankers}

Identification of hypovirulent strains of $C$. parasitica was firstly based on the morphological characterization of the isolates. For detection of hypovirulent strains, the isolates were incubated at $25 \pm 2{ }^{\circ} \mathrm{C}$ for 7 days in the dark, followed by 5 days incubation at room temperature with diffuse light. Isolates that remained white at the end of this period were considered C. parasitica hypovirulent strains (isolates infected with hypovirus).

Vegetative compatibility of orange phenotype isolates was assessed at 7 days of incubation in the dark and then at 5 days of incubation in diffuse light, according to the "barrage"/fusion response (Bissegger et al. 1997), in which fusion of the two colonies means compatibility, and "barrage" between two colonies means strains of different compatibility.

\section{CHV1 hypovirus detection}

The presence of CHV1 (Cryphonectria hypovirus 1) was checked in strains that presented morphological characteristics of hypovirulence (white morphology) and virulent strains (orange morphology) through molecular methods. For the extraction of RNA, isolates were grown in Petri dishes with PDA medium covered with cellophane for 7 days at $25^{\circ} \mathrm{C}$ in the dark. The mycelium was stripped from cellophane and macerated using liquid nitrogen. Total RNA extraction was done using a lysis buffer, precipitated with $100 \%$ ethanol, and washed in columns with a wash solution. The RNA was dissolved in an elution buffer and stored at $-20{ }^{\circ} \mathrm{C}$.

The cDNA was synthesized by diluting $3 \mu \mathrm{L}$ of total RNA in $11 \mu \mathrm{L}$ of RNase-free water and incubated at $100{ }^{\circ} \mathrm{C}$ for $2 \mathrm{~min}$. The dilution of RNA was mixed with $4 \mu \mathrm{L}$ of $5 \mathrm{X}$ Reaction Mix (Sigma) and $2 \mu \mathrm{L}$ Maxima Enzyme Mix (Sigma) and incubated in the following conditions: $10 \mathrm{~min}$ at $25^{\circ} \mathrm{C}, 30 \mathrm{~min}$ at $50^{\circ} \mathrm{C}$, and $5 \mathrm{~min}$ at $85{ }^{\circ} \mathrm{C}$.

The ORF-A region was amplified using the primers hvep-1F (5'- TGACACGGAAGCTGAGTGTC - 3') (Gobbin et al. 2003) and EP-721-4 (5'- GGAAGTCG GACATGCCCTG - 3') (Bryner et al. 2012). For the ORF-B region, the primers orfB-12aF (5'AGACCTCAATCGGGTCTCCCT - 3') and orfB12aR (5'- TTCAACCACACGACGAGTTCG - 3') were used (Rigling, D. personal communication). PCR amplification was performed using $1 \mu \mathrm{L}$ of cDNA in a total of $50 \mu \mathrm{L}$ reaction volume consisting of $10 \mu \mathrm{L}$ of $2 \mathrm{X}$ Jump Start (Sigma) and $1 \mu \mathrm{L}$ of each primer $(20 \mathrm{pmol} / \mu \mathrm{L})$. Thermocycling conditions were set up with an initial denaturation at $94^{\circ} \mathrm{C}$ for $2 \mathrm{~min}$, followed by 33 cycles consisting of $94^{\circ} \mathrm{C}$ denaturation for $1 \mathrm{~min}$, annealing at $55^{\circ} \mathrm{C}$ for $1.5 \mathrm{~min}$, and elongation at $72{ }^{\circ} \mathrm{C}$ for $2 \mathrm{~min}$, with a final prolongation at $72{ }^{\circ} \mathrm{C}$ for $8 \mathrm{~min}$. The PCR products were visualized by agarose gel electrophoresis on $1.5 \%$ gel stained with GelRed ${ }^{\circledR}$ Nucleic Acid Gel Stain (Biotium, Inc) under UV illumination.

For CHV1 identification, sequencing of PCR products was performed by StabVida laboratories (Caparica, Portugal). Alignment and phylogenetic analysis for the ORF-B region were performed using the function "build" of ETE3 v3.1.1 (Huerta-Cepas et al. 2016) as implemented on the GenomeNet (https://www.genome. $\mathrm{jp} /$ tools/ete/). The user provided the multiple sequence alignment. ML tree was inferred using PhyML v20160115 ran with model and parameters: -alpha e -f $\mathrm{m}$-o tlr -nclasses 4 -pinv e -bootstrap 100 (Guindon et al. 2010). Branch supports were computed out of 100 bootstrapped trees.

Sequences of previously reported subtypes I (GeneBank accession no. AF082191), F1 (M57938.1), D (KY002082) and E (KY002083), and hypovirulent isolate RBB 111 (isolate used for canker treatment), were used for comparison with re-isolates.

\section{Identification of non-Cryphonectria parasitica microfungi species}

Identification of non- $C$. parasitica microfungi was based on morphological characteristics, but mainly on molecular methods by amplification and sequencing of the ITS (ITS1, 5.8S, ITS2), ribosomal DNA (rDNA) region using the ITS1 and ITS4 universal primers (White et al. 1990) and BLAST comparing sequences published in the GenBank databases (https://blast.ncbi. nlm.nih.gov/). DNA extraction from the microfungi was performed using the DNeasy Plant Mini Kit (QIAGEN) and REDExtract-N-Amp ${ }^{\text {TM }}$ Plant PCR Kit (Sigma-Aldrich), and amplified region sequencing was performed by StabVida Laboratories (Caparica, Portugal).

Each species was taxonomically classified according to the Index Fungorum Database (www. indexfungorum.org). 
Richness and abundance of non-Cryphonectria parasitica microfungi species

Rank-abundance plots of the species identified in each location were obtained using functions rankabundance and rankabundplot from package BiodiversityR Version 3.6.1 of R software was used.

The species were classified according to their biological behavior by bibliographic research (saprophyte, endophyte, parasitic).

\section{Statistical analysis}

Statistical analyses of $C$. parasitica isolates in different places (application site, $3 \mathrm{~cm}$ inward, $3 \mathrm{~cm}$ outward) were performed using one-way analysis of variance (ANOVA) followed by a post hoc LSD test with Statistica 12 software (StatSoft Inc., Tulsa, OK).

\section{Results}

Efficacy of canker treatment

In Valpaços, one year after application (2015), 93.8\% of the cankers were healed and there was no visible growth of the mycelial parasitic fungus outside the treatment margin. In this sampling site, four cankers remained partially active in 2015 and they were promptly rectified (by a new partial treatment). In 2018, all treated cankers were healed and presented healed tissue throughout the diseased area.

In Vinhais, 31 cankers were treated with the hypovirulent strain CHV1-RBB111. In 2015, three of the 31 treated cankers remained partially active and they were promptly rectified. Four years after application of the hypovirulent strain, it was observed that 29 trees presented healed cankers, and only in two chestnut trees the canker remained active. In both sites, the efficacy of the treatment, evaluated one year after the application, was very high, showing an efficacy of $93.8 \%$ in Valpaços and $90.3 \%$ in Vinhais. Four years after application of the hypovirulent strain, the efficacy of treatments was $100 \%$ in Valpaços and $93.5 \%$ in Vinhais (Table 1).

Incidence of Cryphonectria parasitica (virulent and hypovirulent strains), and non-Cryphonectria parasitica microfungi in healed cankers

From the 168 bark samples collected in both sampling areas, 134 purified isolates were obtained. From the total purified isolates, 77 isolates of $C$. parasitica were obtained from both orchards; 11 isolates showed orange pigmentation, characteristic of virulent isolates, and 66 isolates were white or with reduced sporulation (hypovirulent isolates) when grown on a PDA medium. From the C. parasitica isolates obtained, $88.9 \%$ and $82.9 \%$ (strains with white morphology) were hypovirulent in Valpaços and Vinhais, respectively. In the bark samples, where C. parasitica was not isolated, $38.1 \%$ of the isolates in Valpaços, and $51.1 \%$ of the isolates in Vinhais, were non-C. parasitica microfungi.

The percentage of $C$. parasitica (virulent and hypovirulent) and non- $C$. parasitica isolates obtained in Valpaços and Vinhais are shown in Table 2. The number of hypovirulent isolates obtained was significantly higher than the virulent isolates, both in Valpaços $(P=0.04)$ and in Vinhais $(P=0.01)$. The highest percentage of hypovirulent isolates was obtained inwards

Table 1 Healed cankers, active cankers and efficacy of treatment (\%) in the orchards of Valpaços and Vinhais

\begin{tabular}{llll}
\hline & Valpaços $(n=65)$ & & \\
\hline & Healed cankers & Active cankers & Efficacy \\
1st assessment (2015) & 61 & 4 & $93.8 \%$ \\
2nd assessment (2018) & 65 & 0 & $100.0 \%$ \\
Vinhais $(n=31)$ & & & Active cankers \\
& Healed cankers & 3 & $90.3 \%$ \\
1st assessment (2015) & 28 & 2 & $93.5 \%$ \\
2nd assessment (2018) & 29 & 29 & \\
\hline
\end{tabular}

$n$ - number of treated trees 
Table 2 Number of Cryphonectria parasitica isolates (virulent and hypovirulent) and non-C. parasitica isolates obtained in Valpaços and Vinhais from application site (AS), $3 \mathrm{~cm}$ inward (3I) and $3 \mathrm{~cm}$ outward (3E)

\begin{tabular}{|c|c|c|c|c|c|c|c|c|c|c|c|c|c|c|c|c|c|c|}
\hline \multirow[b]{3}{*}{ Cankers } & \multicolumn{9}{|c|}{ Valpaços } & \multicolumn{9}{|c|}{ Vinhais } \\
\hline & \multicolumn{3}{|c|}{$\begin{array}{l}\text { C. parasitica } \\
\text { Virulent }\end{array}$} & \multicolumn{3}{|c|}{$\begin{array}{l}\text { C. parasitica } \\
\text { Hipovirulent }\end{array}$} & \multicolumn{3}{|c|}{ non-C.parasitica } & \multicolumn{3}{|c|}{$\begin{array}{l}\text { C. parasitica } \\
\text { Virulent }\end{array}$} & \multicolumn{3}{|c|}{$\begin{array}{l}\text { C. parasitica } \\
\text { Hipovirulent }\end{array}$} & \multicolumn{3}{|c|}{ non-C.parasitica } \\
\hline & AS & $3 I$ & $3 \mathrm{E}$ & AS & $3 \mathrm{I}$ & $3 \mathrm{E}$ & $\mathrm{AS}$ & $3 \mathrm{I}$ & $3 \mathrm{E}$ & AS & $3 \mathrm{I}$ & $3 \mathrm{E}$ & AS & $3 I$ & $3 \mathrm{E}$ & $\mathrm{AS}$ & $3 I$ & $3 \mathrm{E}$ \\
\hline 1 & $1 / 4$ & $0 / 4$ & $0 / 4$ & $3 / 4$ & $4 / 4$ & $3 / 4$ & $0 / 4$ & $0 / 4$ & $0 / 4$ & $0 / 4$ & $0 / 4$ & $0 / 4$ & $2 / 4$ & $3 / 4$ & $1 / 4$ & $2 / 4$ & $1 / 4$ & $3 / 4$ \\
\hline 2 & $0 / 4$ & $0 / 4$ & $0 / 4$ & $1 / 4$ & $0 / 4$ & $0 / 4$ & $2 / 4$ & $0 / 4$ & $4 / 4$ & $1 / 4$ & $0 / 4$ & $0 / 4$ & $2 / 4$ & $3 / 4$ & $2 / 4$ & $1 / 4$ & $1 / 4$ & $2 / 4$ \\
\hline 3 & $0 / 4$ & $0 / 4$ & $0 / 4$ & $4 / 4$ & $4 / 4$ & $3 / 4$ & $0 / 4$ & $0 / 4$ & $0 / 4$ & $0 / 4$ & $0 / 4$ & $0 / 4$ & $3 / 4$ & $3 / 4$ & $1 / 4$ & $1 / 4$ & $1 / 4$ & $3 / 4$ \\
\hline 4 & $0 / 4$ & $0 / 4$ & $0 / 4$ & $0 / 4$ & $2 / 4$ & $0 / 4$ & $4 / 4$ & $2 / 4$ & $3 / 4$ & $0 / 4$ & $2 / 4$ & $0 / 4$ & $4 / 4$ & $1 / 4$ & $3 / 4$ & $0 / 4$ & $1 / 4$ & $1 / 4$ \\
\hline 5 & $0 / 4$ & $0 / 4$ & $0 / 4$ & $1 / 4$ & $0 / 4$ & $0 / 4$ & $3 / 4$ & $4 / 4$ & $0 / 4$ & $2 / 4$ & $1 / 4$ & $1 / 4$ & $0 / 4$ & $0 / 4$ & $0 / 4$ & $2 / 4$ & $3 / 4$ & $3 / 4$ \\
\hline 6 & $1 / 4$ & $0 / 4$ & $2 / 4$ & $3 / 4$ & $2 / 4$ & $2 / 4$ & $0 / 4$ & $2 / 4$ & $0 / 4$ & $0 / 4$ & $0 / 4$ & $0 / 4$ & $0 / 4$ & $0 / 4$ & $1 / 4$ & $4 / 4$ & $4 / 4$ & $3 / 4$ \\
\hline 7 & $0 / 4$ & $0 / 4$ & $0 / 4$ & $0 / 4$ & $0 / 4$ & $0 / 4$ & $4 / 4$ & $4 / 4$ & $0 / 4$ & $0 / 4$ & $0 / 4$ & $0 / 4$ & $2 / 4$ & $0 / 4$ & $3 / 4$ & $2 / 4$ & $4 / 4$ & $1 / 4$ \\
\hline$(\%)^{\mathrm{a}}$ & 7.1 & 0.0 & 7.1 & 42.9 & 42.9 & 28.6 & 46.4 & 42.9 & 25.0 & 10.7 & 10.7 & 3.6 & 46.4 & 35.7 & 39.3 & 42.9 & 53.6 & 57.1 \\
\hline
\end{tabular}

${ }^{a}$ percentage of positive isolations in each sampled location (AS, 3I, 3E)

of the punch margin and at the application site $(42.9 \%$ and $46.4 \%$ in Valpaços and Vinhais, respectively). The lowest number of hypovirulent isolates was obtained outwards of the application margin $(3.6 \%)$ which showed a weak colonization of healthy stem tissues. In Valpaços, C. parasitica virulent isolates were not obtained from the inside of the punch margin. On the other hand, in Vinhais only three virulent isolates were obtained from the inside of the inoculated margin that had been obtained from larger extended cankers which had been treated. In treated cankers, in Valpaços, C. parasitica was not found in six samples where nonC. parasitica microfungi were abundantly isolated (two at the application site, two inwards and two outwards). In Vinhais, C. parasitica was not found in three sample places (one at the application site and two inwards).

\section{Cryphonectria hypovirus 1 (CHV1) detection}

Total RNA was extracted from 30 C. parasitica reisolates (five virulent (orange isolates) and 25 hypovirulent (white isolates), randomly selected and used to generate cDNA. The CHV1 virus was detected in 21 re-isolates with hypovirulent characteristics, in nine re-isolates at the application site, seven re-isolates at $3 \mathrm{~cm}$ inwards, and in five re-isolates at $3 \mathrm{~cm}$ outwards. In all re-isolates showing orange pigmentation (virulent phenotypic), the virus was not detected. The presence of the Cryphonectria hypovirus 1 (CHV1) was verified in
21 isolates by PCR using the published primer pairs for the virus ORF-A and ORF-B as indicated in Fig. 1.

The studied hypovirulent strains where chosen from five aleatory cankers, both in Valpaços and Vinhais. In Valpaços, CHV1 was detected in four cankers. In one canker, where only one white strain was isolated, it was not possible to detect CHV1 by PCR. In Vinhais, the presence of CHV1 was detected in all studied cankers.

Phylogenetic analysis for the ORF-B region represented in Fig. 2, grouped the re-isolated hypovirus into one cluster together with the applied hypovirulent strain and the reference isolates of the CHV1 subtype I (CHV1-I) introduced into the analysis.

Non-Cryphonectria parasitica microfungi species in healed cankers

From 75 isolates of microfungi, 14 different species were identified. Vinhais had a greater species richness with 10 different identified microfungi species compared to Valpaços where seven different species were identified as represented in Fig. 3.

Biscogniauxia mediterranea (De Not.) Kuntze was the most abundant species in the two studied orchards, with 24 isolates, followed by Penicillium glabrum (Wehmer) Westling with 15 isolates and Cytospora diatrypelloidea G.C. Adams \& M.J. Wingf. with 14 isolates. B. mediterranea was isolated in both Valpaços and Vinhais from four chestnut trees. P. glabrum was isolated from five trees in Vinhais, and 


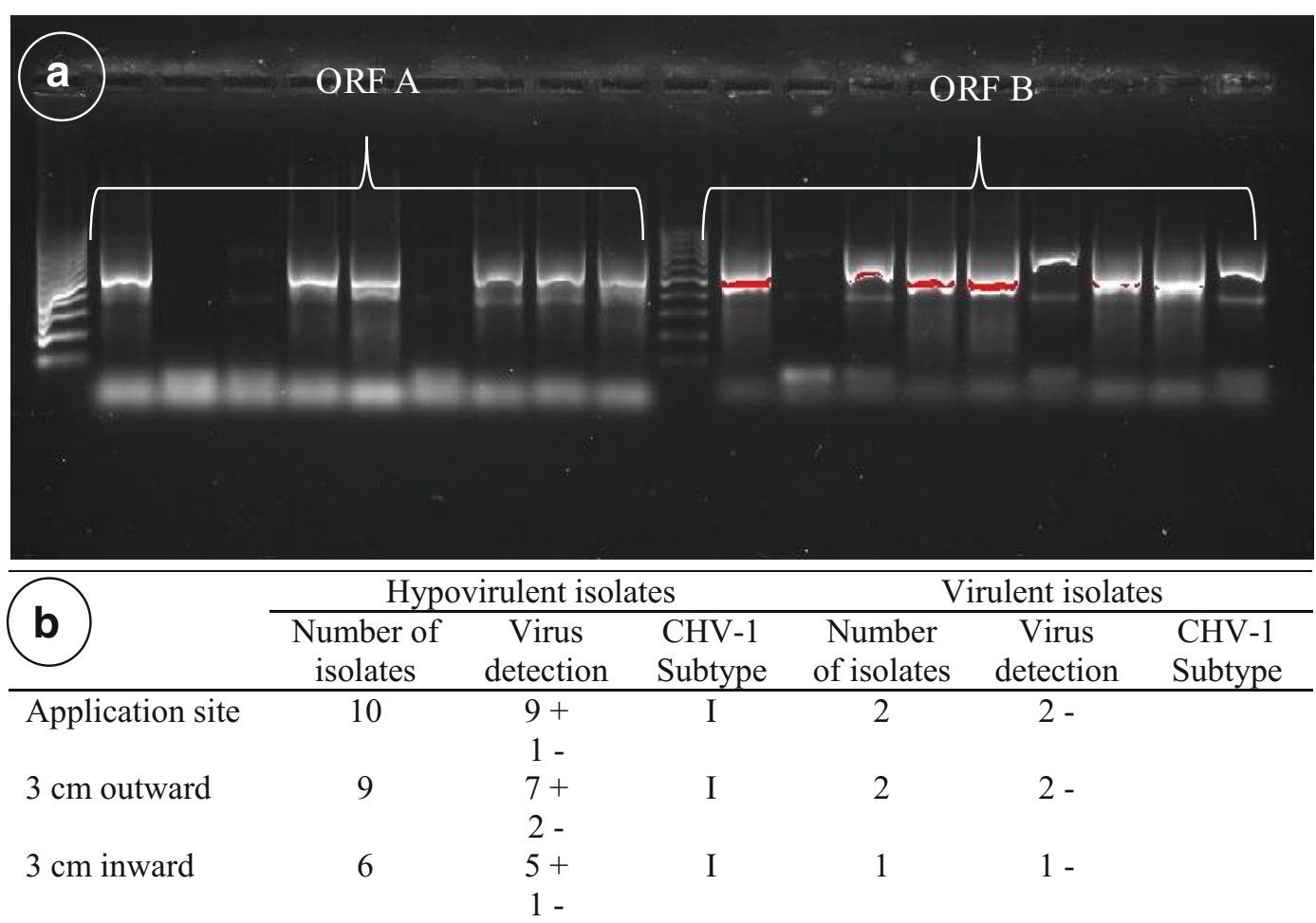

Fig. 1 a - Gel electrophoresis with amplified fragments from Cryphonectria parasitica isolates using primer pair hvep-1F and EP-721-4 for a region in ORF-A of the hypovirus genome and orfB-12aF and orfB-12aR for a region in ORF-B of the hypovirus

\section{C. diatrypelloidea was isolated from five trees in} Valpaços.

In accordance with the species' biological behavior (saprophyte, endophytes, pathogenic) eight species were classified as endophytes, four classified as pathogenic and three classified as saprophytes. Some species have more than one biological behavior and may be endophytes/pathogenic, endophytes/saprophytes, saprophytes/pathogenic and saprophytes/endophytes/ pathogenic.

Endophytic fungi were observed in a larger number of trees where $C$. parasitica (virulent and hypovirulent) was less represented. In Vinhais, conversely, the species P. glabrum, also considered endophytic in Castanea, was isolated from trees where a large number of C. parastica hypovirulent isolates were obtained (Fig. 4).

The endophytes were the most abundant functional group of fungi inhabiting healed cankers with $60.0 \%$ of isolates $(53.1 \%$ in Valpaços and $65.1 \%$ in Vinhais), followed by the group of pathogenic fungi with $22.7 \%$ of isolates (25.0\% in Valpaços and 20.9\% in Vinhais), genome. b - Virus detection and CHV1 subtype of re-isolates from application site, $3 \mathrm{~cm}$ inward and $3 \mathrm{~cm}$ outward (+ presence of virus; - no virus detected; I - Italian subtype I)

and the group of saprophytes fungi with $12.0 \%$ of isolates (12.5\% in Valpaços and $11.6 \%$ in Vinhais).

\section{Discussion}

Hypovirulence (natural or human-assisted) is the most promising approach to reduce the impact of C. parasitica where chestnut blight is established (Jeger et al. 2016). Natural hypovirulence is currently considered to have the advantage by its rapid and efficient spread in chestnut stands. On the other hand, human-assisted hypovirulence is an ecosystem approach using field applications of compatible hypovirulent strains of $C$. parasitica, previously investigated in the laboratory. The method includes the analysis of virulent populations of $C$. parasitica to study the diversity of vegetative compatibility (vc types), the occurrence of natural hypovirulence in the region, laboratory production/formulation of hypovirulent strains, and finally studies for field evaluation. This study was done in two commercial chestnut orchards after the official 


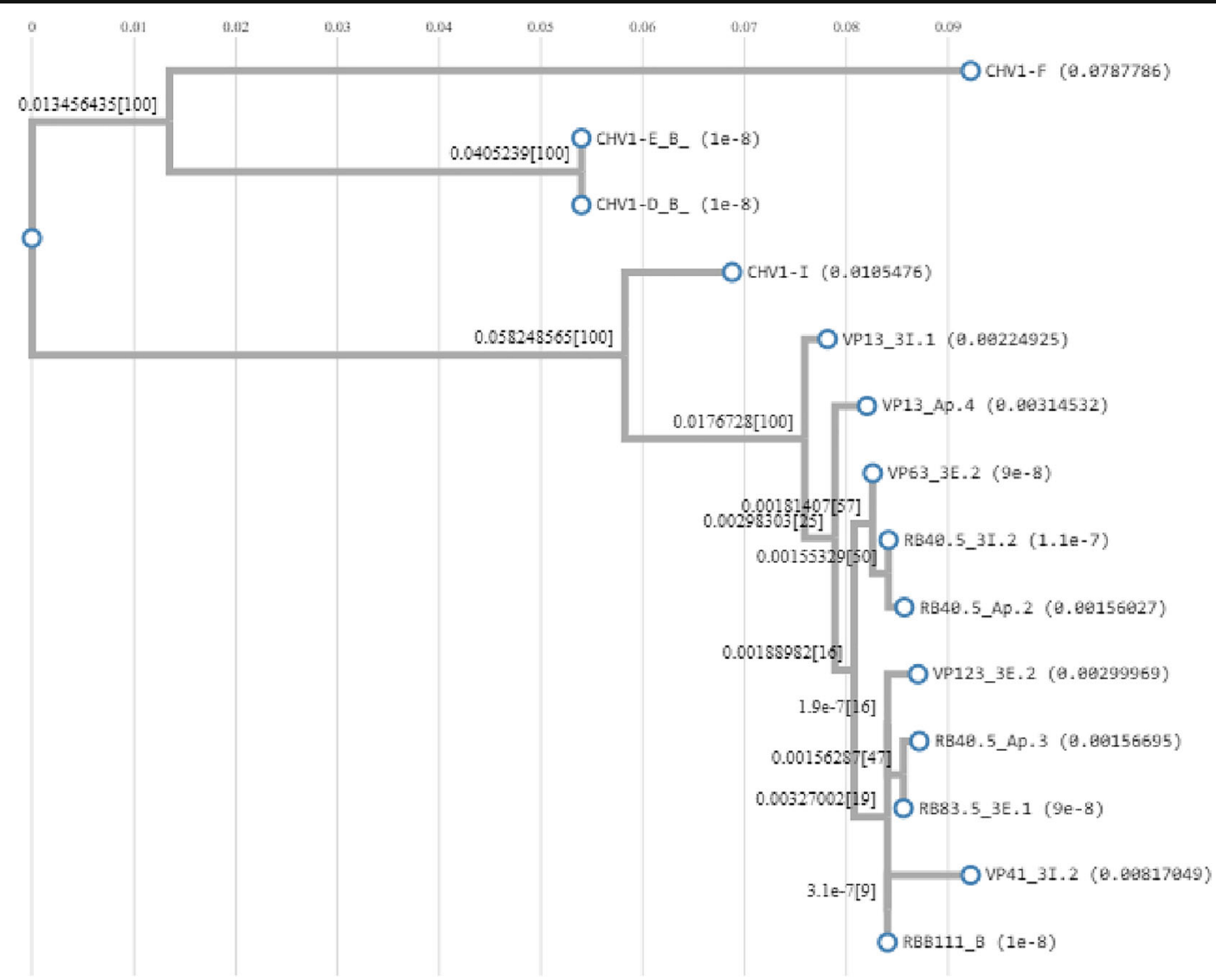

Fig. 2 Phylogenetic tree of a partial nucleotide sequence from ORF-B of Cryphonectria hypovirus 1 (CHV1) isolates from Valpaços (RB40.5_3I.2, RB40.5_Ap.2, RB40.5_Ap.3, RB83.5_3E.1) and Vinhais (VP13_3I.1, VP13_Ap.4,

permit was obtained from the Portuguese Ministry of Agriculture. Therapeutic treatment of cankers by hypovirulence was found to be a successful control of chestnut blight in the two commercial orchards. The
VP63_3E.2, VP123_3E.2, VP41_3I.2), and the hypovirulent isolate used for canker treatment (RBB 111). CHV1-I is the reference sequence for Italian subtype. CHV1-F, CHV1-E_B, CHV1-D_B are reference sequences for the different $\mathrm{CHV} 1$ subtypes

efficacy was very high, and four years after treatment all cankers were healed or healing. All treated chestnut trees recovered their vitality and maintained regular fruit production. The results are as expected and in line with
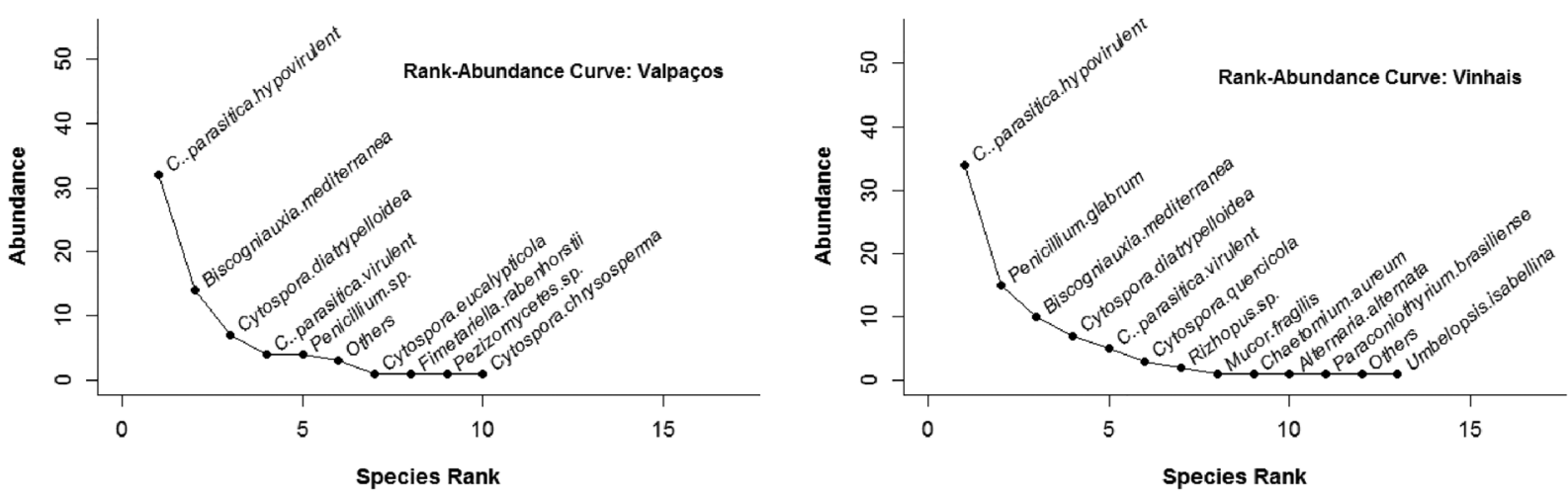

Fig. 3 Rank-Abundance curve of the Cryphonectria parasitica (virulent and hypovirulent) and non-C. parasitica species isolated in Valpaços and Vinhais 
Fig. 4 a-Presence of fungi species per tree and nonC. parasitica fungi grouped by functional group (Endophyte, Pathogen, Saprophyte), b Number of isolates of each functional group in Valpaços and Vinhais. (v - virulent, hv hypovirulent) a

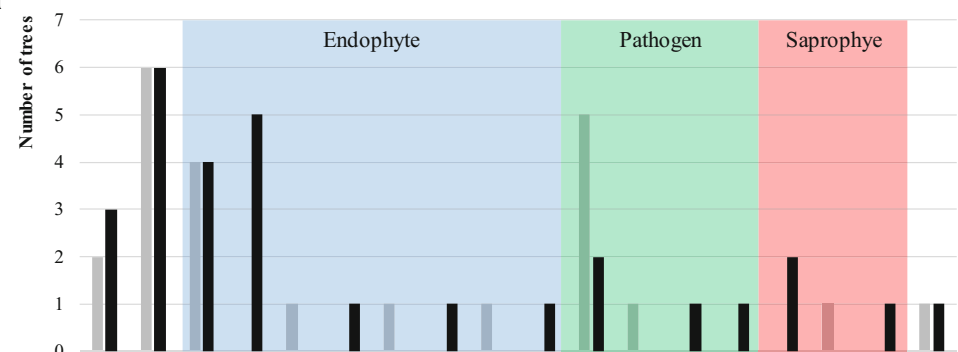

b
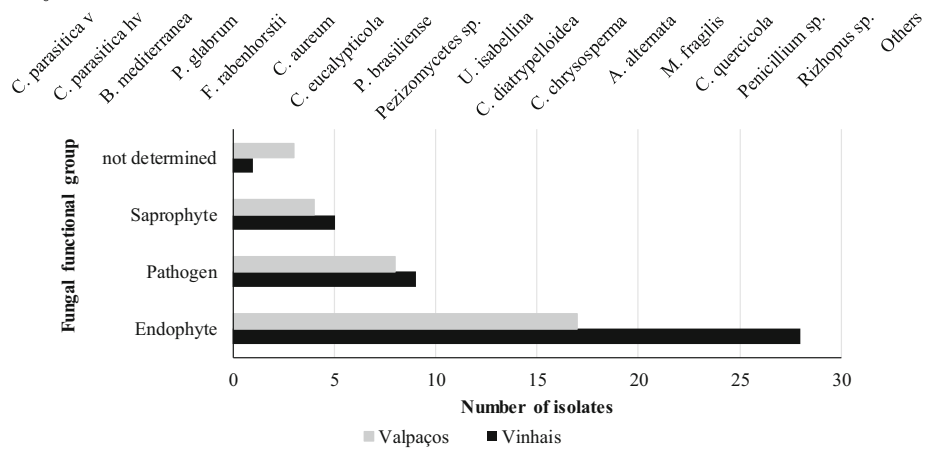

the treatments carried out in France (Robin et al. 2000), Switzerland (Heiniger and Rigling 2009) and Greece (Diamandis 2018).

The introduced hypovirulent strain of $C$. parasitica was re-isolated in almost all treated trees. The white hypovirulent strain was detected in high numbers, both on the application site and also on the inside and outside of the treated cankers, indicating that the hypovirulent strain had remained in the canker areas from its application in 2014 until 2018. The success rate of isolation of the $C$. parasitica hypovirulent strains on the treated canker may vary between sampling sites and be the result of the eventual presence of other fungi in the bark. In our study, monitoring of the healed cankers performed four years after the application of the hypovirulent strain, revealed a percentage of C. parasitica hypovirulent isolates obtained from healed cankers between 43 and $46 \%$ of the overall 134 isolates of micro fungi. C. parasitica virulent isolates were also isolated in a reduced percentage $(0-11 \%)$, as well as a considerable percentage, of other non-C. parasitica species. Studies performed by Ježić et al. (2019) to assess the abundance of hypovirulent $C$. parasitica strains from callused cankers revealed that the percentage of hypovirulent $C$. parasitica isolates recovered from healed cankers on $C$. sativa from different European countries, ranged from $9.47 \%$ to $51.6 \%$ where natural hypovirulence was established. The same authors reported $47.3 \%$ of $C$. parasitica hypovirulent isolates recovered in West Salem (USA) where hypovirulence had been artificially introduced. However, considering only all isolates of $C$. parasitica, the percentage of hypovirulent isolates in our study ranged from $88.9 \%$ in Valpaços to $82.9 \%$ in Vinhais, while the study of Ježić et al. (2019) recorded on average more virulent isolates $(64.7 \%)$ than hypovirulent isolates (35.3\%). Studies performed by Shain and Miller (1992), where natural hypovirulence was established, show that CHV1 moves about $7.2 \mathrm{~cm}$ per week through the mycelium on the periphery of a virulent canker when the same vc type is present; however, it does not move extensively to the older parts in the centre of cankers. The number, although low, of $C$. parasitica virulent isolates recovered in our study, allows us to conclude that CHV1 is still spreading throughout the area of the canker, having not yet colonized all the diseased tissue. It is important to note that some treated cankers are very large, and the inoculation was only applied at the outer limit of the canker and not applied throughout the whole diseased area.

The hypovirus CHV1 is an unencapsidated positive strand (ssRNA) virus of the family Hypoviridae (Suzuki et al. 2018) that is present in Japan, China, and Europe (Allemann et al. 1999), which acts as a natural biocontrol agent of $C$. parasitica. The CHV1 introduced by the application of hypovirulent strains is transmitted 
horizontally by anastomosis of the hyphae, expanding throughout the diseased area (Rigling and Prospero 2018). Highlighting the fact that in some cankers in Vinhais virulent isolates were isolated within the healed cankers, may indicate that the transmission of the virus by anastomosis of the hyphae may take longer than expected, and some time is required for the CHV1 to spread throughout the infected canker. This justifies the practical recommendation of visual monitoring and rectification of treatments during the first year of hypovirulent strain applications. Treating the whole area of the canker is also a new application method to improve efficacy.

PCR detection of CHV1 was obtained in all studied cankers in the Vinhais orchard and in four out of five cankers in the Valpaços orchard. The canker is considered CHV1 positive when ORFA, ORFB or both regions are PCR amplified. In the canker where CHV1 was not detected, many non- $C$. parasitica microfungi were isolated. However, in four white re-isolates (out of 25 studied isolates) the PCR amplification failed. The non-detection of CHV1 in these four strains may be due to the incomplete spread of CHV1 within the healed cankers, since within the cankers orange strains were also found; alternatively, the virus concentration may have been below the detection limit.

Sequence analysis for the ORF-B region indicated that all re-isolated hypoviruses are Cryphonectria hypovirus 1 (CHV1) of the Italian subtype group CHV1-I, the same group of the hypovirulent strain introduced as a biological control agent. In this study area, hypovirulence is rare which makes healing a direct effect of hypovirulence introduction as has been verified by the re-isolation of the same type of hypovirus. Robin et al. (2010), reported a different situation in southern France were the CHV1 subtype F1 used for biological control did not become established, and the CHV1 subtype I was the dominant type; and only one isolate of the French subtype CHV1-F2 was detected. The natural dissemination of hypovirulence is an evident natural event, but not a well-known process, and many factors related to the hypovirus, the fungus, and the environment, may be involved. In the Minho region of Portugal, $200 \mathrm{~km}$ from the Trás-os-Montes region, natural hypovirulence with rapid dissemination has recently been reported in some orchards of hybrid plants resistant to ink disease. Despite some efforts, the driving forces of the process are not yet established (Moura et al. 2015).
The Italian subtype (CHV1-I) has been found in several areas of Europe (Sotirovski et al. 2004; Robin et al. 2010; Ak1ll et al. 2013; Feau et al. 2014) and in the Iberian Peninsula (Homs et al. 2001; Pereira et al. 2015). Although hypovirulence was detected in Castilla y Léon (Zamora et al. 2012), a region geographically close to northern Portugal, it was observed that the hypovirus subtypes found there were different and are included in the French subtype CHV1-F1.

This work validates the establishment and maintenance of the hypovirulent strain and confirm the great efficacy of treatments in natural conditions. The spread of the CHV1 hypovirus cannot be evaluated because all cankers were treated in the Valpaços orchards, and in the Vinhais orchard, the chestnut producers also treated the cankers on the remaining area of the orchard. Direct participation of farmers in these permanent plots is of great importance for the dissemination of new approaches to the control of chestnut blight.

The assessment of the cankers allows us to verify a high percentage of non- $C$. parasitica isolates (about $50 \%$ of recovered isolates in both places) from different species. According to Kolp et al. (2017), the nonC. parasitica usually represent $57 \%$ of the fungal community within a canker. The values for the nonC. parasitica described in our work are close to these values.

Generally, other fungi (non-C. parasitica) are isolated when $C$. parasitica is recovered from cankers (Akilli et al. 2009; Double et al. 2014; Curković-Perica et al. 2017; Kolp et al. 2017) and, according to Double et al. (2014) the occurrence of other fungal species in cankers on surviving trees increases over time. Kolp (2018) reported that non- $C$. parasitica fungi may antagonize hypovirulent $C$. parasitica to a larger degree than the virulent form of the pathogen. This may cause hypovirulent $C$. parasitica never to become the dominant fungus of a chestnut blight canker, which can hinder or delay the recovery of cankers after treatment. Therefore, it is necessary to study the modification of the microbiome in the healed cankers after the introduction of the hypovirulent strains, and to monitor the close interaction with other microfungi present in the tree and in the chestnut ecosystem.

The composition of obtained fungi communities in treated cankers with hypovirulent strains varied between locations. Fungal endophytes were the best represented among the identified taxa. B. mediterranea was the most representative species in both sites studied. This species 
has a strong incidence on Quercus species, including the cork oak and has also been isolated from chestnut trees (Henriques et al. 2015; Potter 2017). This fungus can live as an endophyte in the plant and can act as an opportunistic parasite when trees have symptoms of decline (Henriques et al. 2014).

Fungal endophytes represent a significant group, still misunderstood, in the chestnut ecosystem and the interactions with the introduced hypovirulent strain in the tree are poorly known. Currently, the use of antagonistic endophytes as biocontrol agents is considered an attractive option for the management of some plant diseases (Potter 2017; Murolo et al. 2019; González and Estefanía 2020). In this study, we found a high number of endophytic fungi present in healed cankers. It should be noted that samples of cortical cankers associated with virulent $C$. parasitica have revealed different species of microfungi such as B. mediterranea, Valsa fabianae, Bionectria ochroleuca and Cytospora sp. that co-occur with $C$. parasitica, and have a dominant parasitic behavior (Gouveia et al. 2017). However, further studies are necessary to characterize the non- $C$. parasitica fungi species either in diseased or healthy trees. This is particularly necessary for the endophytic fungi to assess the dynamics of their presence and the process of how these fungi are acquired by the tree. In this context, the microbioma (parasitic, endophytic, and saprophytic microorganisms) in treated cankers, through their close proximity, and contact over time with the hypovirulent strain, need further evaluation, on a case-by-case basis, to understand better the synergic or other potential effects.

Acknowledgments The authors are grateful to the Project BioChestnut -IPM - Implement effective control strategies against the chestnut and almond diseases under the Programme PDR2020101-030959 for financial support.

Funding This study was funded by the Project BioChestnutIPM (PDR2020-101-030959).Data availabilityThe datasets generated during and/or analyzed during the current study are available from the corresponding author on reasonable request.

Compliance with ethical standards This article does not contain any studies with human or animal subjects performed by any of the authors.

Conflict of interest The authors declare that they have no conflicts of interest.

\section{References}

Abreu, C. (1992). A hipovirulência como forma de luta natural contra o cancro do castanheiro. Revista das Ciências Agrárias, 15(1-2), 167-169.

Akilli, S., Katircioðlu, Y. Z., \& Maden, S. (2009). Chestnut blight cankers in black sea region of Turkey. Acta Horticulturae, $815,247-252$.

Akıllı, S., Ulubaș Serçe, Ç. U., Katircioğlu, Y. Z., Maden, S., \& Rigling, D. (2013). Characterization of hypovirulent isolates of the chestnut blight fungus, Cryphonectria parasitica from the Marmara and Black Sea regions of Turkey. European Journal of Plant Pathology, 135(2), 323-334.

Allemann, C., Hoegger, P. J., Heiniger, U., \& Rigling, D. (1999). Genetic variation of Cryphonectria hypoviruses (CHV1) in Europe assessed using restriction fragment length polymorphism (RFLP) markers. Molecular Ecology, 8, 843-854.

Anagnostakis, S. L., Hau, B., \& Kranz, J. (1986). Diversity of vegetative compatibility types of Cryphonectria parasitica in Connecticut and Europe. Plant Disease, 70, 536-538.

Bissegger, M., Rigling, D., \& Heiniger, U. (1997). Population structure and disease development of Cryphonectria parasitica in european chestnut forests in the presence of natural hypovirulence. Phytopathology, 87, 50-59.

Bragança, H., Simões, S., Onofre, N., Tenreiro, R., \& Rigling, D. (2007). Cryphonectria parasitica in Portugal: diversity of vegetative compatibility types, mating types, and occurrence of hypovirulence. Forest Pathology, 37, 391-402.

Bryner, S. F., Rigling, D., \& Brunner, P. C. (2012). Invasion history and demographic pattern of Cryphonectria hypovirus 1 across European populations of the chestnut blight fungus. Ecology and Evolution, 2, 32927-33241.

Câmara, M. S. (1929). Micotes aliquot novi allique in mycoflora lusitaneae ignoti. Revista Agronómica, 17, 7.

Chira, D., Bolea, V., Chira, F., Mantale, C., Tăut, I., Șimonca, V., et al. (2017). Biological control of Cryphonectria parasitica in Romanian protected sweet chestnut forests. Notulae Botanicae Horti Agrobotanici Cluj-Napoca, 45(2), 632-638.

Curković-Perica, M., Ježić, M., Karin, V., Idžojtić, M., Sotirovski, K., Risteski, M. et al. (2017). Biological control of chestnut blight: (In)stable infection of the chestnut blight fungus by Cryphonectria hypovirus 1. In: 7th Congress of European Microbiologists, Valencia, Spain 9-13 July 2017.

Diamandis, S. (2018). Management of Chestnut blight in Greece using hypovirulence and silvicultural interventions. Forests, 9, 492.

Double, M. L., Kolp, M. R., Jarosz, A. M., Davelos Baines, A., Fulbright, D. W., \& MacDonald, W. L. (2014). Fungi associated with hypovirulent cankers of differing ages on American chestnut. Acta Horticulturae, 1043, 57-65.

EC 1107/2009. Regulation (EC) No $1107 / 2009$ of the European Parliament and of the council of 21 October 2009.

Feau, N., Dutech, C., Brusini, J., Rigling, D., \& Robin, C. (2014). Multiple introductions and recombination in Cryphonectria hypovirus 1: perspective for a sustainable biological control of chestnut blight. Evolutionary Applications, 7, 580-596.

Gobbin, D., Hoegger, P. J., Heiniger, U., \& Rigling, D. (2003). Sequences variation and evolution of Cryphonectria parasitica (CHV-1) in Europe. Virus Research, 97, 39-46. 
González, A. J., \& Estefanía, T. (2020). Strains of Neopestalotiopsis sp. are in vitro antagonists of Cryphonectria parasitica. Biological Control, 143, 104187.

Gouveia, E., Coelho, V., \& Monteiro, M. L. (2010). Potential of local Hypovirulent strains of Cryphonectria parasitica for biological control of chestnut blight. Acta Horticulturae, 866, 443-448.

Gouveia, E., Pereira, E., Araújo, A., Coelho, V., Castro, J., Bragança, H., \& Martins, L. (2016). Cancro do Castanheiro em Trás-os-Montes (Portugal): Incidência atual e estudo da estrutura populacional de Cryphonectria parasitica para a introdução da luta biológica por hipovirulência. Gaia Scientia, 10(2), 75-83.

Gouveia, E., Torrent, I.I. \& Coelho, V. (2017). Diversidade de microfungos presentes nos ramos e troncos de castanheiro infectados por Cryphonectria parasitica. $8^{\circ}$ Congresso Florestal Nacional. Viana do Castelo, 11-14 October 2017, pp. 193.

Guindon, S., Dufayard, J. F., Lefort, V., Anisimova, M., Hordijk, W., \& Gascuel, O. (2010). New algorithms and methods to estimate maximum-likelihood phylogenies: assessing the performance of PhyML 3.0. Systematic Biology, 59(3), 307-321.

Heiniger, U., \& Rigling, D. (1994). Biological control of chestnut blight in Europe. Annual Review of Phytopathology, 32, 581599.

Heiniger, U., \& Rigling, D. (2009). Application of the Cryphonectria Hypovirus (CHV-1) to control the chestnut blight, experience from Switzerland. Acta Horticulturae, $815,233-245$.

Henriques, J., Nóbrega, F., Sousa, E., \& Lima, A. (2014). Diversity of Biscogniauxia mediterranea within single Stromata on Cork Oak. The Journal of Mycology, 2014, 324349 .

Henriques, J., Nóbrega, F., Sousa, E., \& Lima, A. (2015). Morphological and genetic diversity of Biscogniauxia mediterranea associated to Quercus suber in the Mediterranean Basin. Revista de Ciências Agrárias, 38(2), 166-175.

Hoegger, P. J., Heiniger, U., Holdenrieder, O., \& Rigling, D. (2003). Differential transfer and dissemination of hypovirus and nuclear and mitochondrial genomes of a hypovirusinfected Cryphonectria parasitica strain after introduction into a natural population. Applied and Environmental Microbiology, 69, 3767-3771.

Homs, G., Rodríguez, J., Rigling, D. \& Colinas, C. (2001). Caracterización de la población de Cryphonectria parasitica y detección de cepas hipovirulentas en 3 subpoblaciones de Cataluña. Montes para la sociedad del nuevo milenio. III Congreso Forestal Español. Granada, Spain.

Huerta-Cepas, J., Serra, F., \& Bork, P. (2016). ETE 3: Reconstruction, analysis, and visualization of Phylogenomic data. Molecular Biology and Evolution, 33(6), 1635-1638.

Jeger, M., Bragard, C., Chatzivassiliou, E., Dehnen-Schmutz, K., Gilioli, G., Jaques Miret, J.A., MacLeod, A., Navajas Navarro, M., Niere, B., Parnell, S., Potting, R., Rafoss, T., Urek, G., Van Bruggen, A., Van der Werf, W., West, J., Winter, S., Maresi, G., Prospero, S., Vettraino, A.M., Vloutoglou, I., Pautasso, M. \& Rossi, V. (2016). Scientific opinion on the risk assessment and reduction options for
Cryphonectria parasitica in the EU. EFSA Journal, 14(12), 4641, $54 \mathrm{pp}$.

Ježić, M., Kolp, M., Prospero, S., Sotirovski, K., Double, M., Rigling, D., Risteski, M., Karin-Kujundžić, V., Idžojtić, M., Poljak, I., \& Ćurković-Perica, M. (2019). Diversity of Cryphonectria parasitica in callused chestnut blight cankers on European and American chestnut. Forest Pathology, 49, e12566.

Kolp, M. (2018). Fungal community succession and interactions in chestnut blight cankers on American chestnut trees in Michigan and Wisconsin. PhD thesis. Michigan State University, East Lansing, Michigan.

Kolp, M., Double, M.L., Fulbright, D.W., MacDonald, W.L. \& Jarosz, A.M. (2017). Tracking disease and the fungal community structure in chestnut blight cankers on American chestnut in Michigan and Wisconsin. In: 102nd Annual Meeting of the Ecological Society of America, Portland, Oregon 5-11 August 2017.

Krstin, L., Katanić, Z., Ježić, M., Poljak, I., Nuskern, L., Matković, I., Idžojtić, M., \& Ćurković-Perica, M. (2017). Biological control of chestnut blight in Croatia: An interaction between host sweet chestnut, its pathogen Cryphonectria parasitica and the biocontrol agent Cryphonectria hypovirus 1. Pest Management Science, 73, 582-589.

Kunova, A., Pizzatti, C., Cerea, M., Gazzaniga, A., \& Cortesi, P. (2016). New formulation and delivery method of Cryphonectria parasitica for biological control of chestnut blight. Journal of Applied Microbiology, 22, 180-187.

Milgroom, M. G., \& Cortesi, P. (2004). Biological control of chestnut blight with hypovirulence: A critical analysis. Annual Review of Phytopathology, 42, 311-338.

Moura, L., Pereira, G., Costa, S., Martins, M., \& Gouveia, E. (2015). Chestnut blight in the Minho region. Population structure and genetic variability of Cryphonectria parasitica. Revista de Ciências Agrárias, 38(2), 238-247.

Murolo, S., Concas, J., \& Romanazzi, G. (2019). Use of biocontrol agents as potential tools in the management of chestnut blight. Biological Control, 132, 102-109.

Pereira, E., Rigling, D., Prospero, S., \& Gouveia, E. (2015). Controlo biológico do cancro do castanheiro. Deteção, identificação e caracterização do Hypovirus - CHV1. Revista de Ciências Agrárias, 38(2), 258-263.

Potter, B. (2017). Biocontrol potential of endophytes of healthy Castanea dentata for application against Cryphonectria parasitica. Master of Science in Biology. University of Wisconsin-La Crosse, pp. 70.

Rigling, D., \& Prospero, S. (2018). Cryphonectria parasitica, the causal agent of chestnut blight: invasion history, population biology and disease control. Molecular Pant Pathology, 19(1), 7-20.

Robin, C., \& Heiniger, U. (2001). Chestnut blight in Europe: diversity of Cryphonectria parasitica, hypovirulence and biocontrol. Forest Snow and Landscape Research Editorial, 76(3), 361-367.

Robin, C., Anziani, C., \& Cortesi, P. (2000). Relationship between biological control, incidence of hypovirulence, and diversity of vegetative compatibility types of Cryphonectria parasitica in France. Phytopathology, 90, 730-737.

Robin, C., Lanz, S., Soutrenon, A., \& Rigling, D. (2010). Dominance of natural over released biological control agents of the chestnut blight fungus Cryphonectria parasitica in 
South-Eastern France is associated with fitness-related traits. Biological Control, 53, 55-61.

Shain, L., \& Miller, J. B. (1992). Movement of cytoplasmic hypovirulence agents in chestnut blight cankers. Canadian Journal of Botany, 70, 557-561.

Sotirovski, K., Papazova-Anakieva, I., Grunwald, N. J., \& Milgroom, M. G. (2004). Low diversity of vegetative compatibility types and mating type of Cryphonectria parasitica in the southern Balkans. Plant Pathology, 53, 325-333.

Suzuki, N., Ghabrial, S. A., Kim, K., Pearson, M., Marzano, S. L., Yaegashi, H., et al. (2018). ICTV virus taxonomy profile: Hypoviridae. Journal of General Virology, 99, 615-616.
White, T. J., Bruns, T., Lee, S., \& Taylor, J. (1990). Amplification and direct sequencing of fungal ribosomal RNA genes for phylogenetics. In M. Innis, D. Gelfand, J. Shinsky, \& T. J. White (Eds.), PCR protocols: a guide to methods and applications (pp. 315-322). San Diego: Academic Press.

Zamora, P., Martín, A. B., Rigling, D., \& Diez, J. J. (2012). Diversity of Cryphonectria parasitica in western Spain and identification of hypovirus-infected isolates. Forest Pathology, 42(5), 412-419.

Zamora, P., Martín, A. B., San Martín, R., Martínez-Álvarez, P., \& Diez, J. J. (2014). Control of chestnut blight by the use of hypovirulent strains of the fungus Cryphonectria parasitica in northwestern Spain. Biological Control, 79, 58-66. 